\title{
Arsenic Disruption of Steroid Receptor Gene Activation: Complex Dose-Response Effects Are Shared by Several Steroid Receptors*
}

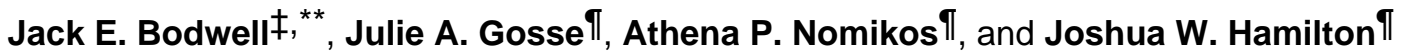 \\ $\$$ Department of Physiology, Dartmouth Medical School, Lebanon NH 03756 \\ II Department of Pharmacology \& Toxicology, Dartmouth Medical School, Hanover NH 03755 and the Center \\ for Environmental Health Sciences, Dartmouth Medical School, Hanover NH 03755
}

\begin{abstract}
Chronic intake of arsenic (As) has been associated with increased risk of cancer, diabetes, developmental and reproductive problems, and cardiovascular disease. Recent studies suggest increased health risks with drinking water levels as low as 5-10 ppb. We previously reported that As disrupts glucocorticoid receptor (GR) mediated transcription in a very complex fashion. Low As levels $(0.1$ to $0.7 \mu \mathrm{M})$ stimulated transcription whereas slightly higher levels ( 1 to $3 \mu \mathrm{M}$ ) were inhibitory. The DNA Binding Domain (DBD) was the minimal region of GR required for the response to As. Mutations in the DBD that alter the conformation of the dimerization domain (D-Loop) to a DNA-bound GR conformation abolished the stimulatory effect and enhanced the inhibitory response to As. Here we report that receptors for progesterone (PR) and mineralocorticoids (MR) display a similar complex As response as the GR, suggesting a common mechanism for this effect. The complex response to As is not due to altered steroid or receptor levels. Moreover, a well-characterized GR dimerization mutant displayed a wild-type biphasic response to As for several divergent reporter genes, suggesting that dimerization is not critical for the response to As. Fluorescence polarization studies with purified PR and GR demonstrated that the specific PR/GR-DNA interaction is not altered in the presence of As. These results indicate that the numerous and diverse human health effects associated with As exposure maybe mediated, at least in part, through its ability to simultaneously disrupt multiple hormone receptor systems.
\end{abstract}

\section{Introduction}

Arsenic (As) ${ }^{1}$ exposure is a major human health concern $(1,2)$, with potential exposures occurring in occupational settings, from Superfund sites and other toxic waste sites, and from natural sources in the environment. Both the World Health Organization and Agency for Toxic Substances and Disease Registry $(1,2)$ list arsenic as the top environmental chemical of human health concern. The most significant route of exposure to As is via drinking water since

\footnotetext{
* This work was supported in part by NIH-NIEHS Grant R01 ES011819 (JEB) and NIH-NIEHS Superfund, Basic Research Program Project Grant P42 ES07373 (JWH, Project 2).

** To whom Correspondence should be addressed: Department of Physiology, Dartmouth Medical School, 750W Borwell Building, 1 Medical Center Drive, Lebanon NH 03756. Tel.:603 650-7734; Fax. 603 650-6130; E-mail Jack.E.Bodwell@ Dartmouth.edu.

${ }^{1}$ Abbreviations. The abbreviations used are: As, arsenic; Dex, dexamethasone; GR, glucocorticoid receptor; hGR, human GR; rGR, rat GR; mGR, mouse GR; LBD, ligand binding domain; DBD, DNA binding domain; GRE, glucocorticoid receptor response element; SRE, steroid receptor response element; FP, fluorescence polarization; PR, progesterone receptor; MR, mineralocorticoid receptor; AR, androgen receptor; SR, steroid receptor; PEPCK, phosphoenolpyruvate carboxykinase; TAT, tyrosine aminotransferase; PNMT, phenylethanolamine $N$-methyltransferase.
} 
contamination of ground water readily occurs from certain natural underground geological sources containing As $(1,2)$. These concerns recently spurred the U.S. EPA to reduce the maximum allowable levels of As in public drinking water from 50 to $10 \mathrm{ppb}(0.67$ to 0.13 $\mu \mathrm{M})$. While these regulations will ultimately benefit people using public water supplies, full implementation of the new regulations will require 7-14 years, and there are also millions of people in the U.S. whose water comes from private, unregulated bedrock wells who will not directly benefit from this regulatory change. This is problematic since in many areas of the country, As in drinking water is found naturally at levels greatly exceeding these federal guidelines. Almost half the population of New Hampshire, for example, obtain their drinking water from private, unregulated wells, $20 \%$ of which contain an excess As (3). Chronic exposure to As has been associated with increased risk of lung, skin, bladder, liver, kidney, and other internal cancers, as well as type 2 diabetes, vascular disease, cardiovascular disease, and reproductive and developmental problems (1,2,4). Thus, As exposure will continue to be a major environmental health concern in the U,.S. and worldwide.

Inorganic As predominates in the environment and exists in two forms, arsenite $\left(\mathrm{As}^{+3}\right)$ or arsenate $\left(\mathrm{As}^{+5}\right)$. These two forms are readily interconverted in the environment depending on redox conditions and other factors. In most biological systems the two forms appear to have similar effects but arsenite is approximately two- to four-fold more potent than arsenate.

Speciation of the exact intracellular forms is complicated by the fact that both forms can readily enter cells and they can also be inter-converted by redox pathways in vivo. At physiological $\mathrm{pH} \mathrm{As}^{+3}$ (as arsenite) is neutral (glycerol mimic), and $\mathrm{As}^{+5}$ (as arsenate) is charged (isostructural with phosphate and sulfate). Thus $\mathrm{As}^{+3}$ uses the multifunctional aquaglyceroporin channels (5) to enter the cell while $\mathrm{As}^{+5}$ enters through the non-specific anion transporter and possibly other sulfate and phosphate transport systems (6).

Once inside the cell, $\mathrm{As}^{+3}$ prefers binding to sulfhydryl groups, with a particular preference for vicinal dithiols in proteins. On the other hand, $\mathrm{As}^{+5}$ competitively interferes with phosphorylation reactions at enzyme active sites and target sites of phosphorylation. Inorganic As can also be metabolized in vivo in a series of sequential methylation steps that eventually lead to one or more highly methylated forms that are considered less toxic than the inorganic and intermediate forms and are readily excreted (7). However, several of the intermediates in this pathway are now recognized to have their own unique toxicities. In particular, the monoand di-methylated $\mathrm{As}^{+3}$ forms $\left(\mathrm{MMA}^{+3}, \mathrm{DMA}^{+3}\right)$ are more toxic than inorganic As, and have been reported to be more carcinogenic in animals (8). Thus, the overall patho-physiological effects of As may result from a combination of effects from several different forms of As in vivo.

Our previous work using very low, environmentally relevant doses of As demonstrated a highly selective effect on in vivo gene expression (9). Because many of the genes affected appeared to be inducible, with some under hormone control, this led us to studies where we demonstrated that As can act as a potent endocrine disruptor of hormone-activated gene transcription mediated by the glucocorticoid receptor (GR). These effects occur at very low doses both in cell culture (rat hepatoma cells) and in a whole animal model (the chick embryo) (9-11). Such endocrine disruption may be a major mechanism underlying the effects of As on human health and may explain the many and diverse diseases associated with excess As consumption.

The GR is a member of the steroid receptor superfamily and exists predominately in the cytoplasm as a multicomponent complex consisting of chaperones, immunophilins and other proteins. This complex is required for proper receptor conformation, to open the hormone binding cleft to allow ligand binding, and to allow interactions with dynein for transport to the nucleus (overview in (12)). Once in the nucleus activated GRs associate as homodimers with specific gene regulatory sequences known as glucocorticoid response elements (GRE) (13, 
14), and, in association with various coactivators and basic transcription factors, GR can modulate expression of hormone-responsive genes such as phosphoenolpyruvate carboxykinase (PEPCK) and tyrosine aminotransferase (TAT).

Detailed studies using a GR deficient rat hepatoma cell line (EDR-3), demonstrated that the response to As is more complex than originally thought. Low levels of As $(0.01-1 \mu \mathrm{M})$ actually stimulate expression from a large number of different reporter genes as well as the endogenous Tyrosine aminotransferase (TAT) gene and also enhances hormone-stimulated gene transcription (11). Fine titration of doses within this range revealed at least 3 distinct peaks of stimulation whose magnitude was highly dependent on the levels of activated GR within the cell (11). At slightly higher but not cytotoxic concentrations ( $2-3 \mathrm{uM})$ the effect of As is essentially reversed, and inhibition of gene transcription was observed. These same biphasic patterns of stimulation and inhibition were observed in GR deletion mutants missing either the $\mathrm{N}$ - or C-terminal domains, suggesting that the central DNA binding domain is essential for propagating the effects of As. Interestingly, while there was a biphasic response for GREmediated gene transcription by GR, there was no effect of As on GR-mediated inhibition of AP1- and NF-kB-regulated gene transcription (11).

Additional experiments with GR mutants indicated that the two free sulfhydryls located within the GR DBD are not required for either the stimulatory or inhibitory phase of the As response. In fact, a double mutant of these cysteines showed a greater response to As than did wild-type GR (11). However the stimulatory effects of As were virtually eliminated while the inhibitory response is enhanced by two other well-characterized mutations that allow the dimerization surface (D-loop) of the DBD to adopt a constitutively DNA-bound conformation in the absence of DNA. The formation of this DNA-bound conformation by the D-loop is thought to provide a new surface that can bind additional co-regulator proteins ((15) and references within). These results suggest that the conformation of the D-loop of the GR plays an important role in the mode of action of As. Because of the location of these effects within the DBD, we initiated the current studies to determine whether GR dimerization is necessary for the biphasic response to As and whether As effects might also be explained by subtle changes in the GR-DNA interaction. We also evaluated the effects of As on other steroid receptors, since members of the steroid receptor super-family share close homology within the DBD region and several receptors bind the same core GRE sequence. We focused in particular on the receptors for progesterone (PR) and mineralocorticoids (MR) since they are also amenable to study in the same cell culture system as GR.

\section{Experimental Procedures}

Caution: As is classified as a probable human carcinogen $(1,2,4)$. All arsenicals should be handled as potentially highly toxic compounds.

\section{Reagents and Buffers}

Dexamethasone, aldosterone, progesterone, and dihydrotestosterone (Steroids, Newport, RI) were dissolved in ethanol as $1 \mathrm{mM}$ stocks and stored at $-20^{\circ} \mathrm{C}$. Iron-supplemented calf serum was purchased from Sigma. DMEM/F12 was purchased from Gibco (Gaithersburg, MD). Charcoal stripped serum was prepared as previously described (16). D-luciferin potassium salt was from PharMingen (San Diego, CA). All other reagents were from Sigma (St. Louis, MO) or Fisher Scientific (Pittsburgh, PA).

\section{Cell Lines and Vectors}

EDR3, a generous gift from Dr. Gary Firestone, is a minimal hepatoma cell line derived from the Fu5 cell line (17). It contains no detectable GR. The cell line 10.1.11.14 is based on the 
EDR3 cell line and stably expresses 10,000-15,000 mGRs/cell. H4IIE is a rat hepatoma cell line with 30,000-40,000 endogenous rGRs/cell. Culture of these lines was as described previously $(10,16,18)$.

The plasmid pSV2 WT2X encodes for the mouse GR (18). Drs Chris Jewel and John Cidlowski kindly supplied PCMV5mGR (18) and pCMV5hGR (19), which express the mouse and human GR, respectively. PCMV4/neo/MR was a generous gift from Dr David Pearce and expresses the rat MR (20). The expression vector pCR3.1 PRB expresses the B form of the human PR and was graciously supplied by Drs. Bert O'Malley and Nancy Weigel(21). Point mutations used in this study were made with the Quickchange Mutagenesis kit (Stratagene, La Jolla, CA) according to manufacturer's instructions and confirmed by DNA sequencing.

The G2T reporter gene (18) has two tandem GREs from the TAT gene controlling luciferase expression. TAT-Luc was constructed by PCR cloning of the GRE-containing fragment from the TAT gene promoter (-3079 to $-2034,(22))$ and placing into the BamHI and KpnI sites of PXP2-Tata-Luc (23). Likewise the -977 to -513 GRE containing fragment of the PNMT gene promoter was inserted into the BamHI and KpnI sites of PXP2-Tata-Luc to make PNMT-Luc. The inserted regions of both vectors were verified by DNA sequencing.

\section{Transfection, cell harvesting, and assays}

Long duration electroporation was used to transfect cells with the appropriate constructs, and the whole-cell binding assay to determine GR steroid binding with dexamethasone has been has described in detail $(11,18)$. The processing of cells as well as protein and luciferase assay are described in Bodwell et. al. (11). Basically, EDR-3 cells were electroporated with vectors encoding for the GR or other steroid receptor (SR) and the G2T or other reporter gene, plated out in 24 well plates with six replicates for each treatment. Both the total amount of DNA (27 $\mu \mathrm{g})$ and the amount of reporter gene transfected (17 ug) was kept constant while the concentration of the individual SR gene was varied as indicated with the difference being made up with the base vector for each SR. The ratio of reporter gene to steroid receptor varied from $\sim 34$ to 1 at the lowest levels to $\sim 3$ to 1 at the highest receptor levels (the largest SR concentration in Fig. 1A and 1B). Except for these two points, all other experiments employed a ratio of $>5$ to 1 . The amount luciferase activity continues to increase at least up to a reporter:receptor ratio of 2 to 1 (data not shown). The next day cells were treated with As $(0.045,0.09,0.18,0.27$, $0.36,0.45,0.54,0.675,0.9,1.8$, and $2.7 \mu \mathrm{M}$ : an additional $10 \mu \mathrm{M}$ point was used in FP experiments) or buffer control and $50 \mathrm{nM}$ Dex or other steroid ( $50 \mathrm{nM}$ unless otherwise stated). Cells were processed 16-18 hrs later and assayed for luciferase and protein.

In order to compare GR types with different transcriptional activity (either because of different GR or hormone levels or the effect of mutation), data was normalized to the no As control for each series of As treatments. These values are included in figure legends.

\section{Purification of hPR and hGR}

The initial preparation of purified hPR was graciously provided by Dr Steve Nordeen but we used the same protocols (24) for subsequent preparations. The purification of human GR was performed as described previously for the PR (24) using FLAG ${ }^{\circledR}$ tagged receptor encoding baculovirus in Sf9 insect cells ( $0.5 \mathrm{~L}$ culture) but substituting $100 \mathrm{nM}$ triamcinolone acetonide for R5020 in the GR preparation. N-terminal FLAG ${ }^{\circledR}$ tagged human GR contained the sequence CCGCCACCATGGATTACAGGGATGACGACGATAGG in the place of the first nine amino acids ${ }^{2}$. Other modifications for the hGR purification included the addition of $1 \mathrm{mM}$ glutathione (GSH), with or without 7.5mM CHAPS, in the peptide elution step. Receptors were

\footnotetext{
${ }^{2}$ Personal communication. Dr. Steve Nordeen.
} 
run on 4-20\% SDS-PAGE to determine the purity (> 90\%) and concentration of the receptors. Gels were stained with SYPRO ${ }^{\circledR}$ Tangerine protein gel stain (Molecular Probes, Carlsbad, CA), according to the manufacturer's instructions, and the integrated density volume (IDV) for each band was determined with a ChemiImager 5500 (Alpha Innotech, San Leandro, CA). The slope of the dilution curve for the receptors (IDV/ $\mu \mathrm{l}$ ) was then divided by the slope of the standard curve (BSA, IDV/ng) to determine the concentration.

\section{Immunoprecipitation and western blotting}

Our basic immunoprecipitation procedure with the anti-GR antibody (FIGR) was used (25) but in FP buffer (see below) with the addition of $2.0 \mathrm{mg} \mathrm{BSA} / \mathrm{ml}$ and $0.2 \%$ Tween-20 (final) to reduce nonspecific binding of the GR to the resin tubes. hGR (prepared without CHAPs) was incubated with a ten-fold molar excess of FIGR or nonspecific immunoglubulin (Protein A-purified mouse serum) for $4 \mathrm{hr}$ at $4^{\circ} \mathrm{C}$ and then rotated at $4{ }^{\circ} \mathrm{C}$ with Protein A sepharose for an additional $4 \mathrm{hrs}$. FP analysis of the supernatants was performed as described below after adding CHAPS to $7.5 \mathrm{mM}$ and maintaining GSH at $1 \mathrm{mM}$.

Samples from immunoprecipitations were run on 4-20\% Tris-gylcine SDS-PAGE (Invitrogen, Madison, WI) and were transferred (25) to a PVDF membrane (Immobilon, Millipore, Milford, MA). Blots were blocked with $20 \mathrm{ml}$ of Super Block (Pierce, Rockland, IL) with $0.05 \%$ Tween-20 while shaking for $1 \mathrm{hr}$ at room temperature and then $5 \mathrm{ug}$ of FIGR ((25) was added to Super Block and incubated an additional $1 \mathrm{hr}$. After washing six times $5 \mathrm{~min}$ with $20 \mathrm{ml}$ of TBS, a 1:50,000 dilution (20ml) of the Fab'2 fragment of anti-mouse IgG and IgM conjugated to horse radish peroxidase (Pierce) was added and incubated for $45 \mathrm{~min}$. After washing as above, the blot was developed using Super Signal West Dura substrate (Pierce) and imaged on a ChemiImager 5500 (Alpha Innotech, San Leandro, CA).

\section{Fluorescent oligonucleotide Duplexes}

Sense strand oligonucleotides were synthesized by Integrated DNA Technologies Inc. (IDT, Coralville, IA) with fluorescein (FITC) incorporated at their 5' ends. Unlabeled antisense strands were also obtained from IDT. The PR/GR response element (GRE) from the TAT gene promoter (22), was used for FITC-G2T, which has two tandem GREs, or FITC-GT, which has a single GRE. Sequences (sense) for: FITC-G2T, 5'-FITC- TCTACACTAG AACATCCTGT ACAGCAGTCG ACTAGAACAT CCTGTACAGC AA -3' (23); FITC-GT, 5'FITCAAGCTTTGCT GTACAGGATG TTCTAGTCGA-3' (23); and the FITC-Random (random composition) 5'-FITC- CTAGACTTACGCTGATGACTTCGGTACGCA-3' (26).

Oligonucleotide duplexes were obtained by annealing equimolar amounts of sense and antisense strands by slow cooling after heating to $95^{\circ} \mathrm{C}$.

\section{Fluorescence Polarization}

Fluorescence polarization (FP) was performed essentially as described (26). Samples containing overall concentrations of $1 \mathrm{nM}$ FITC-oligonucleotide duplex, $10 \mathrm{mM}$ Tris, $\mathrm{pH} 7.8$, $10 \%$ glycerol, $0.34 \mathrm{mg} / \mathrm{mL} \mathrm{BSA}, 1 \mathrm{mM} \mathrm{MgCl} 2,150 \mathrm{mM} \mathrm{NaCl}$ (or varied $\mathrm{NaCl}$ concentrations in indicated experiments), $1 \mathrm{mM} \mathrm{GSH}$ (used where indicated), 0-10 uM As (as sodium arsenite), $7.5 \mathrm{mM}$ CHAPS (used where indicated), and various amounts of hPR or hGR were mixed at room temperature. Samples were placed in triplicate $40 \mathrm{uL}$ aliquots into 96 -well high efficiency $\mathrm{HE}^{\mathrm{TM}}$ polystyrene black microplates (Molecular Devices, Sunnyvale, CA) and were protected from light to avoid photobleaching. The FP function of the Molecular Devices Spectramax M5 Microplate Reader was used to measure binding of the receptors to the oligonucleotides at room temperature and at equilibrium. Equilibrium conditions were determined to be within a few minutes of mixing samples at room temperature (data not shown), and measurements were taken shortly after equilibrium was reached and before any significant decrease in signal was detectable. Softmax Pro software (Molecular Devices) uses the measured intensities of emitted 
light in the parallel and perpendicular polarized directions to calculate the polarization values $(\mathrm{mP})$. The standard deviation of each $\mathrm{mP}$ value at each receptor concentration and of the $\mathrm{mP}$ value with no added receptor are combined by standard error propagation to give the error bars shown in Fig 8. Percent bound values were calculated as previously described (26). Competition assays with unlabeled oligonucleotides and determination of apparent dissociation constants for binding affinity analysis, were performed as previously described (26). For testing the effects of As, receptors were incubated with As and other buffer components for $30 \mathrm{~min}$ at room temperature before the addition of the FITC-oligonucleotide duplexes. Immunoprecipitation to confirm that the receptor is responsible for polarization changes were performed with the hGR as described above, and the resultant supernatants were analyzed by FP.

\section{Results}

\section{The biphasic response of GR to As is observed with other members of the steroid receptor family}

Our previous work with the GR demonstrated that both the endogenous TAT gene and various transfected reporter genes respond to Dex and As treatment with a similar biphasic response (11). At As levels lower than $1 \mu \mathrm{M}$ there was stimulation, whereas at 1-3 $\mu \mathrm{M}$ there was repression. The stimulatory phase showed multiple peaks of increased activity (Fig 1A), which was similar for the mouse, rat and human GR. The degree of stimulation at low As or repression at higher As levels was highly dependent on, and inversely related to the amount of activated GR within the cell, which could be manipulated by either varying the level of GR construct transfected into the cell or by altering the hormone concentration used to stimulate GR (11). Previously, it was shown that basal expression of the reporter construct was not affected by As alone, or by expression of SR without the corresponding hormone, nor was there expression from constructs without an intact GRE or with a mutated GRE even in the presence of As, SR, or SR plus hormone $((10,11)$ and data not shown). The receptors for mineralcorticoids (MR), progesterone (PR) and androgen (AR) all bind the same core GRE sequence and share a similar domain structure, with considerable homology particularly in the DBD and the ligand binding domain. The sequences and structures of the DBDs for these receptors in particular share strong homology. Since we had previously shown that the effects of As could be localized to the GR DBD, We investigated whether these other steroid receptors might also show a similar response to As. The EDR3 rat hepatoma cell line (17) is an excellent cell line in which to answer this question since it is one of the few cell lines that are truly GR negative (neither protein nor mRNA are detectable) but is also without functional MR, PR, or AR (data not shown). However, the necessary machinery for proper steroid receptor function and modulation of regulated genes remains intact in these cells and requires only restoration of the appropriate steroid receptor expression via transfection (17). We had previously shown that there is a linear relationship between the amount of transfected DNA and the cellular levels of SR (11). In addition there is a linear response between the level luciferase expression and cellular SR levels (see Experimental Procedures).

EDR3 cells were transfected with the appropriate steroid receptor encoding DNA and a luciferase reporter gene containing two tandem GREs from the tyrosine amino transferase promoter region (11). Cells were treated overnight with either a single dose of the appropriate steroid or different hormone concentrations. Cells were processed and luciferase determined, and the results normalized to the no As (with steroid) level for each level of transfected DNA or hormone concentration. Fig 1 (Panel A) shows the typical biphasic As response for the hGR after treating cells overnight with $50 \mathrm{nM}$ Dex (data reproduced from (11). Stimulation of hormone-activated, GR-mediated transcription occurred at multiple peaks at the lower concentrations of As $(<1 \mu \mathrm{M})$ whereas repression was observed at higher As concentrations 
(>1 $\mu \mathrm{M})$. Increasing the amount of activated GR in the cells by increasing the amount of transfected DNA encoding the GR construct decreased the stimulatory phase such that at the highest transfected level there was mainly repression suggesting that these two dose-related effects may occur by separate mechanisms.

When $\mathrm{hPR}$ was transfected into EDR-3 cells, treated with As and $50 \mathrm{nM}$ progesterone, and examined as for the GR above, it also displayed the same biphasic As response curve seen with the GR (Fig 1B). There were multiple peaks in the stimulatory phase at lower As concentrations and a repressive phase at the higher concentrations. The hPR also displayed the same dependence on activated receptor levels as seen with the GR in that increasing the amount of activated hPR resulted in less stimulation and more repression.

Likewise, when the rMR was activated with $0.5 \mathrm{nM}$ aldosterone in the presence of different concentrations of As, it displayed the same complex biphasic pattern observed with the hGR and hPR (Fig 1C). Similarly, when the amount of activated rMR was increased by stimulation with $5 \mathrm{nM}$ aldosterone, there was a marked diminution in the stimulatory phase of the response to As (Fig 1C) and corresponding increase in the amount of repression at higher As levels, similar to what we had shown previously for the GR (11).

Although we have not performed an extensive series of As dose-response titrations for the AR as for the other receptors above, preliminary experiments with several key As concentrations showed that the AR was stimulated at $0.5 \mu \mathrm{M}$ As by $\sim 2$-fold over hormone-alone control and was repressed to basal levels at $2 \mu \mathrm{M}$ As (data not shown). Thus all four of the steroid receptors that use the GRE-type hormone response sequence show a very similar biphasic response to As. In a separate detailed study to be published elsewhere, we have also shown that the estrogen receptor (ER) displays the same basic biphasic pattern of low-dose stimulation and higher dose repression. However, the dose-response and fine detail of the ER response also differs in interesting ways from the patterns seen with the other steroid receptors discussed above (J.C. Davey et al., manuscript in preparation).

\section{Biphasic response to $A s$ is not due to changes in steroid binding capacity}

Given that the magnitude of the As response was highly dependent on the level of receptor activation in the cell, we considered that one explanation might be that As alters the intracellular concentration of hormone, leading in turn to the observed effects. For example, As might alter the activity of trans-membrane transporters such as the P-glycoprotein family of $\mathrm{ABC}$ transporters, resulting in fluctuations of the intercellular steroid concentration $(27,28)$. We investigated this possibility by performing whole cell steroid binding assays with $\left[{ }^{3} \mathrm{H}\right]-\mathrm{Dex}$ using a stable line (designated as 10.1.11.14) derived from EDR3 cells (11). These cells contain stably integrated wild-type mGR at $\sim 10,000$ mGRs/cell. We also tested the H4IIE cell line since these cells have high endogenous rGR expression $(\sim 35,000 \mathrm{rGRs} / \mathrm{cell})$ and are also responsive to As (10). Cells were treated overnight with different levels of As and the whole cell steroid binding assay was performed the next day (Fig 2). If As altered intracellular steroid levels then the level of bound GR would be expected to change accordingly. However, there was no significant difference in GR binding capacity of EDR3 or H4IIE cells over the entire 0.1 to $2 \mu \mathrm{M}$ range of As, suggesting that the biphasic responses to As were not due to changes in the amount of steroid (or binding of steroid to receptors) within the cell.

\section{GR dimerization is not needed for the biphasic response to As but other mutations to the dimerization domain do alter the response}

Studies of mouse, rat and human GRs reveal three modular domains (29): the ligand-binding domain (LBD) comprising approximately 200 amino acids at the C-terminus, a segment of $\sim 66$ amino acids near the middle containing the DNA-binding domain (DBD), and the remaining 
portion of the GR which contains the N-terminus. The DBD (Fig 3) contains two zinc fingers (30) with each zinc molecule coordinated by four cysteine residues. There are two additional free cysteines located within the DBD that are not involved in zinc coordination. The DBD bestows the specificity for the GR to bind its DNA recognition element, the GRE $(14,31,32)$. The DBD also provides GR with a dimerization interface (33) and nuclear localization signal (34).

We have previously demonstrated that two mutations to the DBD that produce the same conformational changes in the dimerization loop that occurs when the GR binds to DNA (Fig 3 , horizontal boxes), substantially alter the biphasic response of the GR to As resulting in a loss of the stimulatory phase. We were interested to determine whether another wellcharacterized mutant of this loop would alter the As response. The mutation of $\mathrm{A}$ to $\mathrm{T}$ in the position shown in Fig 3 by the tilted box $\left(\mathrm{GR}_{\mathrm{dim}}\right.$; $\mathrm{A} 477 \mathrm{~T}$, rat sequence) results in a dimerization deficient mutation that was used to make one of the first viable GR knockouts (35). The dimerization mutant is characterized by a diminished response to promoters with intact GREs such as the TAT gene (or G2T; Fig 4) but a full or enhanced response to promoters (bottom of Fig 4) such as found in the phenylethanolamine $N$-methyltransferase (PNMT) gene which have active half-site GREs (36). We confirmed the $\mathrm{GR}_{\text {dim }}$ phenotype by comparing its response to wild-type rGR for three luciferase reporter genes: G2T (described above) with two tandem GREs from the TAT gene; TAT Luc, and PNMT Luc that contains the hormone responsive portions of the TAT gene promoter and PNMT promoter, respectively (see Experimental Procedures).

Wild-type rGR or $\mathrm{GR}_{\text {dim }}$ was transfected at different levels into EDR-3 cells along with one of the three reporter genes. In order to accurately compare the response of the two GRs, we measured receptor number with a whole cell-binding assay in each experiment and only compared treatments containing comparable numbers of expressed GR. After treatment overnight with $50 \mathrm{nM}$ Dex, the cells that were transfected with the $\mathrm{GR}_{\mathrm{dim}}$ expressed only $40 \%$ of the luciferase activity of wild-type rGR on promoters with only full GREs (TAT and G2T, Fig 5) but was fully responsive to the PNMT reporter with multiple half-site GREs. These data agree well with those of the Adams et al. study (36) that showed $\mathrm{GR}_{\mathrm{dim}}$ had only $35 \%$-of wildtype GR for their eTAT Luc vector which contains a GRE from TAT. While they showed stimulation by $\mathrm{GR}_{\mathrm{dim}}$ for the wild-type GR on the PNMT reporter, others (35) have reported that there is no loss of function on this promoter. These differences may very well be due to slight differences in the vectors or the difference responses among different cell types (i.e., EDR-3 versus CV-1). Since the direction of the response is consistent with their results this suggests that $\mathrm{GR}_{\mathrm{dim}}$ is functioning as a dimerization mutant. We then determined the effects of As on $\mathrm{GR}_{\mathrm{dim}}$ mediated expression of these genes using the same experimental paradigm as for the other steroid receptors (SR). As shown in Fig 6, the $\mathrm{GR}_{\mathrm{dim}}$ exhibited a wild-type response to As for all three reporter genes, i.e., there was a stimulatory phase at low As levels and repression at higher levels. It should be noted that the single peak here is likely the result of the higher levels of activated receptor; we had previously shown that this can obscure the fine details in this region, particularly the dual peak $(10,11)$. These results demonstrate that dimerization is not involved in the complex response of the SRs to As, and this clearly contrasts with the pattern seen with the conformational mutants (453A and 493R) shown in Fig 7 where the stimulatory response to low levels of As was virtually eliminated by a conformational alteration in DBD structure (results with WT, 453A, and 493R have been previously published (11)). 


\section{As does not directly alter SR-steroid response element interaction (fluorescence polarization analysis)}

Our previous results with the cysteine-substituted and DNA conformational mutants (11) demonstrated that changes in the conformation of the DBD can significantly alter the receptor's response to As. This raises the question of whether As directly alters the steroid receptorresponse element interaction. Since both the GR and PR bind to the same DNA response element, GRE, we used fluorescence polarization (FP) to determine whether As alters the binding interaction of these receptors with a model GRE sequence. FP is a quantitative method for measuring bimolecular interactions in solution. This technique is based on the observation that normally a small, fluorescently labeled molecule, which in this case is a DNA oligonucleotide duplex containing one or two GREs or control sequence, tumbles rapidly in solution and, when excited by light in a single (vertical) plane, the fluorescence emission occurs mainly in other planes (measured horizontally), i.e., is depolarized. When a large molecule such as hGR binds the GRE, the fluorophore's effective radius increases, causing it to tumble more slowly. Consequently, more emitted light remains in the vertical plane (i.e., remains polarized). The fraction of total fluorescence in the vertical plane is expressed mathematically as milli-polarization units $(\mathrm{mP})$. The $\mathrm{mP}$ value is thus the weighted average of the bound and unbound states, allowing one to construct binding diagrams and to determine binding constants. Higher $\mathrm{mP}$ values correspond to a larger fraction of the fluorescent oligonucleotide duplexes being bound to steroid receptors.

Experiments validating the FP assay are presented in the web-based "Supporting Information" section. These experiments include optimization of salt and reducing agent as well as demonstration of specificity for the response element and the receptor.

We have generated equilibrium receptor binding curves using highly purified hPR and hGR, for fluorescein (FITC)-labeled DNA oligonucleotide duplexes containing one (FITC-GT) and two GREs (FITC-G2T) as well as random sequences (FITC-random) at near physiological levels of salt. The use of both hPR and hGR allows comparison between the two receptors, and because they have a very similar respond to As (Fig 8) we can also exploit slightly different characteristics of the two receptors to evaluate any role that reducing agents might have on the effect of As on the SR-steroid response element (SRE) interaction. In our hands, the hPR has a much lower requirement for reducing agents than the hGR, allowing us to eliminate GSH from the assay with minimal effects. The hPR also appears to be much less prone to non-specific absorption to surfaces than the hGR and does not require CHAPS detergent (37) in the assay.

Representative equilibrium binding curves shown in Fig 8 display the binding of purified hGR and hPR to the double-GRE (FITC-G2T, panel A,B) or to the single GRE (FITC-GT, panel C,D) probes. Binding of hPR is presented in panels A and C while hGR is in panels B and D. These binding curves display the change in $\mathrm{mP}$ values from the no $\mathrm{SR}$ control (left hand axis) or as the percent of FITC-labeled duplexes bound to SRs (right hand axis). Both the hGR and hPR saturation binding curves represent essentially specific binding since under the assay conditions there is very little binding to the random sequences (see Supporting Information).

We chose to use both probes in this study because of our concern that we might be approaching the limit of FP sensitivity with FITC-G2T, the two GRE probe. FP is very sensitive at detecting the binding of the first GR dimer to the GRE but the binding of the second GR dimer produces a much smaller change in $\mathrm{mP}$. In order to avoid missing any potential effects of As we also studied the single GRE probe. Although much of our work has been with the two GRE reporter (Figs 1, 6-7 and (11)), the single GRE displays the same biphasic response to As as the two tandem GREs (data not shown). Each panel in Fig 8 has overlayed, along with the control, the binding in the presence of As at $0.45,2.7$, or $10 \mu \mathrm{M}$. It is clear that there are no major effects 
of As on receptor-DNA binding at any of these concentrations for either the hGR or hPR, nor is there a difference between the two different response elements.

Calculated apparent dissociation constants for the hPR and hGR with the single and double GREs varied between 20 and $80 \mathrm{nM}$. These values are 2.5 to 10 fold higher than reported for the hPR (7.5nM, (26)) using FP analysis. Our values are higher even though some of the purified hPR used in this study was generously provided by one of the authors (Dr Steve Nordeen) of the study describing the $7.5 \mathrm{nM} \mathrm{K}_{\mathrm{d}}$ value. Most likely these differences are a result of different affinities for the probe due to slight differences in the probe sequences as well as differences in the amount of active receptor in the different preparations. Irrespective of minor differences in $K_{d}$ values, the important result is that within each experiment, binding curves and $K_{d}$ values were not altered in the presence of As.

The hGR- and hPR-mediated dose-response to As contains substantial fine structure (Fig 1). Therefore, in order to not miss any critical As concentrations, we tested a single level of hGR and hPR, equivalent to that able to bind $\sim 60-70 \%$ of the DNA probe, and carefully assayed in the presence of all the As concentrations that we used to determine the cellular As response curves (as well as a higher dose of $10 \mu \mathrm{m}$ As; Figure 9). There is no significant difference between control and As-treated samples over the entire range of As concentrations for either hPR (Figure 9A) or hGR (Figure 9B). Control experiments with the hPR demonstrated that the presence of CHAPS and GSH, necessary for the hGR assay, did not mask any As effects (see Supporting Information). Also extending the incubation time of As with the receptor from 30 $\mathrm{min}$ at room temperature to overnight at $4^{\circ} \mathrm{C}$ did not alter the results (data not shown). Although the GR response to As is very sensitive to changes in the conformation of DBD (Fig 7 (11)), As does not appear to have a direct effect on the specific interaction of the receptor with its response element, and, thus, the DBD's function is not directly compromised by As.

\section{Discussion}

Although there is now considerable evidence that chronic, low-level As ingestion, such as by ingestion of contaminated drinking water, is associated with various patho-physiological processes, the mechanism(s) underlying these myriad of adverse health effects remains unclear. Several mechanisms have been proposed, and there is evidence to support each of these. Thus, it may be that arsenic alters disease risk by multiple, parallel pathways. However, there is also evidence that the specific effects of arsenic may vary with dose and time of treatment, and there are also likely to be tissue-, species and developmental age-specific effects of arsenic that remain to be sorted out.

Low dose As treatment of cultured cells and intact animals has been shown to have profound but highly selective effects on gene expression (9-11) in which the pattern of gene alterations at low (non-toxic) doses is almost completely non-overlapping with the pattern seen in the same systems at higher doses producing overt cytotoxicity (38). Low dose As in particular appears to target highly inducible genes whose regulation is controlled by environmental, hormonal or other exogenous signals, with minimal effects on the expression of most genes, including all of the constitutively expressed genes we have examined (9). Thus, As induces highly selective effects involving specific signaling and regulatory pathways.

Glucocorticoids and other steroid hormones regulate many of the genes affected by low dose As, and we previously demonstrated that As is a potent endocrine disruptor, altering steroid receptor-regulated gene regulation at extremely low doses. The present work extends our observations of effects of As on GR to PR, MR and AR, and other studies in our laboratory also demonstrate an effect of As on ER, as others have also reported (39) Thus, all five steroid receptor classes are affected by low dose As in a similar manner. Steroid hormones and their 
receptors have been shown to play crucial roles in many disease processes, including those associated with chronic arsenic exposure such as cancer, diabetes, cardiovascular and vascular disease, and reproductive and developmental problems. Endocrine disruption by As therefore is likely to be a major contributor to the disease risks associated with chronic As exposure.

It is very interesting that MR, PR, and AR (Fig 1) all show the same biphasic response to As as seen with the GR. This suggests that As is altering some common target or process in steroid receptor mechanism of action. Using the GR as a model for other SRs we have been able to rule out a number of possible common steps in this mechanism.

One possibility is that As could modify cellular levels of hormone. For example, it has previously been reported that As can act as a transcriptional activator of the membrane transporter, P-glycoprotein (27), and that changes in the levels of P-glycoprotein can alter intercellular steroid concentrations $(28,40)$. However, as reported here, As has no significant effect on cellular steroid levels, or on binding of steroid to the receptor (Figure 2). A second possible mechanism is that As could act as a hormone-mimetic agonist, or as a competitive or non-competitive antagonist of hormone binding or activation of the receptor. However, our current studies, in conjunction with previous studies, clearly demonstrate that As does not activate or act as an agonist for GR, nor does it appear to act as a competitive antagonist. For example, As alone had no effect on cytosolic localization of GR, and As alone had little or no effect on expression of GRE-driven constructs. Likewise, As appears to have no effect on the ability of hormone to bind to or activate GR, nor does it appear, at least in a qualitative fashion, to affect hormone-stimulated nuclear translocation of GR (10).

In contrast to these results, Simons and co-workers, who investigated the in vitro effect of As on semi-purified cytosolic GR preparations, previously reported that hormone binding to the GR could be decreased by the addition of arsenite (41-43). The inhibitory effect of As on steroid binding was half maximal at $7 \mu \mathrm{M}$ - a cytotoxic dose, considerably higher than those used in this study. Their results appeared to be due to interactions of As with one or more vicinal dithiols on GR located in the ligand binding domain, although mutational analyses of cysteines in this domain failed to identify specific residues that mediated this effect. Martin and co-workers have reported that As can act as a hormone-mimetic agonist with ER, activating the receptor in a manner similar to estradiol and leading to increases in ER-regulated gene expression (39). Interestingly, ER is the most divergent of the steroid receptors, and the most closely related to the common ancestral form from which they evolved, whereas the other four are closely related to each other and may reflect a much more recent evolutionary duplication and specialization within higher vertebrates (44). Thus, the differences in As response may reflect a difference between ER and the GR, PR, MR and AR receptors examined in this study, which clearly did not respond to As alone at the doses we used.

A third possible mechanism that might explain the common responses we observed for GR, MR, PR and AR is that As could alter cellular levels of receptor. This was particularly important to investigate since we demonstrated that changes in the cellular levels of activated receptor, e.g., as manipulated by altering levels of transfected GR expression construct, can lead to quantitative differences in the As response. However, our current results demonstrate clearly that treatment with As alone does not significantly alter the level of GR either for cells expressing endogenous GR (H4IIE) or those expressing stably integrated GR (10.1.13.14, Fig $2)$. In contrast, it has been reported that As decreased cellular ER levels after $\geq 24$ hrs of treatment $(39,45,46)$. While those ER changes might eventually lead to alterations in the response of ER-mediated gene expression to As, it is unlikely that such long-term changes would significantly alter gene expression under short term treatment conditions (i.e., up to 18$24 \mathrm{hr}$ after As treatment). This is especially true in view of the fact that the decrease in ER caused by $1 \mu \mathrm{M}$ As mirrors the same extent of decrease caused by estrogen itself yet there is 
clearly a strong response to estrogen ((39) and Jennifer Davey, unpublished results). Moreover, since we observed no effect of As on cellular GR levels in our system, it is also unlikely to be responsible for the effects we observed. These divergent results may indicate either another difference between ER and the other steroid receptors, or other differences that are specific to the cell lines or other experimental conditions of each study. In any event, such a mechanism is unlikely to explain our results.

The next possible mechanism we considered involves the steps immediately downstream of nuclear translocation and receptor activation, i.e., dimerization and DNA binding. Our previous mutational studies indicated that the central DBD of GR, which includes both DNA binding and dimerization regions, was a critical region of the hormone-activated receptor for mediating the As response. Thus, the present studies focused primarily on whether the structure of the DBD and or its ability to dimerize or bind to DNA in the hormone-activated state was important for the As response. Our current results (Fig 1) demonstrating the very similar responses of GR, MR, PR and AR to As, and that DBD is so closely conserved among these four steroid receptors, supports the idea that the DBD is critical for mediating the As response.

Our previous work (11) demonstrated that perturbations of DBD conformation has profound effects on the response of the GR to As. The double mutation of the two free cysteines in the DBD (C450A-C500S) enhanced the response to As by increasing the magnitude of both the stimulatory phase and as well as the repressive phase. Two other mutants, S459A and P493R, (15) also significantly alter the response to As, but in a very different manner. These mutants alter the conformation of the dimerization loop (D-loop) through disruption of the hydrogen bond between serine 459 and arginine 496 (albeit by two distinct mechanisms). This allows the N-terminus end of the D-loop to move into the position that it normally assumes upon binding to DNA. These mutations virtually eliminated the stimulatory response of the GR to As (Fig 7). Taken together with the results of the hyper-fractionated dose-response studies and those titrating the levels of activated receptor, these results suggest that the stimulatory lowdose effects of As occur via a different mechanism or pathway than the inhibitory higher dose effects. Since the mutants that have a constitutive DNA-binding conformation do not exhibit the low dose stimulatory effects, we hypothesize that these low dose effects may involve steps required for DNA binding of hormone-activated receptor, such as early co-activator interactions, recruitment to DNA, or other related steps. In contrast, the retention of the higher dose inhibitory effects of As in these mutants suggests that the higher dose effects are more closely related to subsequent steps involving interactions with the transcriptional machinery.

Until recently, it was thought that dimerization of GR was a requisite step in GR activation of gene transcription. However, development of dimerization mutants, and discovery of genes with half-site GREs that are regulated by monomers of GR has changed this view, and also provided important experimental tools for investigating the role of GR dimerization in the As response. Interestingly, and somewhat surprisingly, the dimerization mutant displayed a normal, wild-type response to As. Thus, dimerization is not important for the As response nor is this the target within the DBD per se. Both because of the striking effects of the S459A and P493R mutants on conformation of the D-loop as well as their altered response to As, and because $\mathrm{GR}_{\mathrm{dim}}$ is thought to also alter the surface provided by the D-loop, it was surprising that the $\mathrm{GR}_{\mathrm{dim}}$ mutant displayed a wild-type response (Fig 6). We are not aware of any structural studies that have been done with the $\mathrm{GR}_{\mathrm{dim}}$ mutation (rat, A477T: mouse A458T); however circular dichroism and melting curve studies (47) done with the double dimerization mutant, N454D/A458T, showed no significant structural rearrangements from wild-type. Of course these techniques are not sensitive enough to detect subtle changes in the D-loop conformation that are probably involved in the ability of A458T to inhibit dimerization. Nonetheless, major outcome of these studies is the conclusion that the dimerization process probably has a very minor role in the response of GR to As. 
The final mechanism we considered to explain the effects of As is that it could alter the ability of hormone-activated GR to bind to DNA. The effect of As on DNA binding by GR was previously evaluated by the Simons group, (42). While they reported that overtly cytotoxic levels $(100 \mu \mathrm{M})$ of As altered nonspecific binding of GR to DNA, they did not examine binding to specific response elements under physiological ionic strength conditions. Our FP data clearly demonstrate that neither the stimulatory nor the inhibitory phase of the SR-mediated response to low-dose As is through a direct effect on the SR-SRE interaction. This is important since our previous data strongly indicate the involvement of the DBD in mediating the response to As. While the FP results demonstrated that there is no direct effect on the DBD, As may very well have an indirect effect. This further supports the hypothesis that As affects the interactions or GR with co-activators or other transcription factors. Based on the similar responses of GR, MR, PR and AR to As, it is likely that this will involve partners or pathways that are common to these receptors. We have considered two mechanisms. One is that As, which is well-known to affect signal transduction pathways, may alter activation or repression of SRs and/or various coregulator proteins. An alternative mechanism could be that As directly inhibits or activates SR:coregulator binding interactions, for example by binding to sulfhydryls as $\mathrm{As}^{3+}$ or to phosphate sites as $\mathrm{As}^{5+}$.

An interesting and unexpected result of these studies is the profound effect of differing cellular levels of activated receptor on the As response. Given that receptor and hormone levels normally vary by tissue, sex, developmental stage and physiological status, this has interesting implications for human health effects of As. Thus, not only is the dose and duration of arsenic exposure likely to be important, but because varying levels of hormone and receptor could conceivably change both the direction and magnitude of the As effect in a given target tissue, one could imagine a wide qualitative and quantitative divergence of biological responses that could be tissue-, sex-, and age-specific even though As is acting as an endocrine disruptor in each target tissue. Since As is considered the number one environmental agent of concern in the U.S. and worldwide, with perhaps 20-25 million people being exposed to excess drinking water As in the U.S. alone, accurately assessing its mechanism of action is of paramount importance to understanding and predicting its overall health impact.

\section{Supplementary Material}

Refer to Web version on PubMed Central for supplementary material.

\section{Acknowledgements}

The excellent technical assistance of Ms Fiona Barr was greatly appreciated. We thank Ms Jennifer Davey for reviewing this manuscript and Drs Gary Firestone, Chris Jewel, John Cidlowski, David Pearce, Bert O’Malley, and Nancy Weigel for providing reagents for this study. We are especially grateful to Dr. Steve Nordeen for providing our initial preparation of hPR and for assistance with the PR and GR purifications.

\section{References}

1. ATSDR. Toxicological Profile for Arsenic (Update). Agency for Toxic Substances and Disease Registry, SUDHHS, PHS; Washington D.C: 1999.

2. NRC. Arsenic in Drinking Water. National Research Council; Washington D.C.: 1999.

3. Karagas MR, Stukel TA, Tosteson TD. Assessment of cancer risk and environmental levels of arsenic in New Hampshire. Int J Hyg Environ Health 2002;205:85-94. [PubMed: 12018020]

4. Abernathy COLY, Longfellow D, Aposhian HV, Beck B, Fowler B, Goyer R, Menzer R, Rossman T, Thompson C, Waalkes M. Arsenic: health effects, mechanisms of actions, and research issues. Environ Health Perspect 1999:593-597. [PubMed: 10379007] 
5. Liu Z, Shen J, Carbrey JM, Mukhopadhyay R, Agre P, Rosen BP. Arsenite transport by mammalian aquaglyceroporins AQP7 and AQP9. Proc Natl Acad Sci U S A 2002;99:6053-6058. [PubMed: 11972053]

6. Andrew AS, Warren AJ, Barchowsky A, Temple KA, Klei L, Soucy NV, O’Hara KA, Hamilton JW. Genomic and proteomic profiling of responses to toxic metals in human lung cells. Environ Health Perspect 2003;111:825-835. [PubMed: 12760830]

7. Huang RN, Lee TC. Cellular uptake of trivalent arsenite and pentavalent arsenate in KB cells cultured in phosphate-free medium. Toxicol Appl Pharmacol 1996;136:243-249. [PubMed: 8619232]

8. Salim EI, Wanibuchi H, Morimura K, Wei M, Mitsuhashi M, Yoshida K, Endo G, Fukushima S. Carcinogenicity of dimethylarsinic acid in p53 heterozygous knockout and wild-type C57BL/6J mice. Carcinogenesis 2003;24:335-342. [PubMed: 12584185]

9. Hamilton JW, Kaltreider RC, Bajenova OV, Ihnat MA, McCaffrey J, Turpie BW, Rowell EE, Oh J, Nemeth MJ, Pesce CA, Lariviere JP. Molecular basis for effects of carcinogenic heavy metals on inducible gene expression. Environ Hlth Perspect 1998;106:1005-1015.

10. Kaltreider RC, Davis AM, Lariviere JP, Hamilton JW. Arsenic alters the function of the glucocorticoid receptor as a transcription factor. Environ Hlth Perspect 2001;109:245-251.

11. Bodwell JE, Kingsley LA, Hamilton JW. Arsenic at Very Low Concentrations Alters Glucocorticoid Receptor (GR)-Mediated Gene Activation but Not GR-Mediated Gene Repression: Complex DoseResponse Effects Are Closely Correlated with Levels of Activated GR and Require a Functional GR DNA Binding Domain. Chem Res Toxicol 2004;17:1064-1076. [PubMed: 15310238]

12. Murphy PJ. Regulation of glucocorticoid receptor steroid binding and trafficking by the hsp90/hsp70based chaperone machinery: implications for clinical intervention. Leukemia 2005;19:710-712. [PubMed: 15759036]

13. Cairns W, Cairns C, Pongratz I, Poellinger L, Okret S. Assembly of a glucocorticoid receptor complex prior to DNA binding enhances its specific interaction with a glucocorticoid response element. J Biol Chem 1991;266:11221-11226. [PubMed: 2040629]

14. Perlmann T, Eriksson P, Wrange Ö. Quantitative analysis of the glucocorticoid receptor-DNA interaction at the mouse mammary tumor virus glucocorticoid response element. J Biol Chem 1990;265:17222-17229. [PubMed: 2170368]

15. van Tilborg MA, Lefstin JA, Kruiskamp M, Teuben J, Boelens R, Yamamoto KR, Kaptein R. Mutations in the glucocorticoid receptor DNA-binding domain mimic an allosteric effect of DNA. J Mol Biol 2000 Aug 25;301:947-958. [PubMed: 10966797]

16. Hu J-M, Bodwell JE, Munck A. Control by basal phosphorylation of cell cycle-dependent, hormoneinduced glucocorticoid receptor hyperphosphorylation. Mol Endocrinol 1997;11:305-311. [PubMed: 9058377]

17. Cook PW, Swanson KT, Edwards CP, Firestone GL. Glucocorticoid receptor-dependent inhibition of cellular proliferation in dexamethasone-resistant and hypersensitive rat hepatoma cell variants. Mol Cell Biol 1988;8:1449-1459. [PubMed: 3380086]

18. Bodwell J, Swift F, Richardson J. Long Duration Electroporation for Achieving High Level Expression of Glucocorticoid Receptors in Mammalian Cell Lines. J Steroid Biochem Molec Biol 1999;68:77-82. [PubMed: 10215040]

19. Schaaf MJ, Cidlowski JA. The glucocorticoid receptor beta-isoform: a perspective on its relevance in human health and disease. Ernst Schering Res Found Workshop 2002:197-211. [PubMed: 12355717]

20. Chen SY, Wang J, Liu W, Pearce D. Aldosterone responsiveness of A6 cells is restored by cloned rat mineralocorticoid receptor. Am J Physiol 1998;274:C39-46. [PubMed: 9458711]

21. Allan GF, Leng X, Tsai SY, Weigel NL, Edwards DP, Tsai MJ, O’Malley BW. Hormone and antihormone induce distinct conformational changes which are central to steroid receptor activation. J Biol Chem 1992;267:19513-19520. [PubMed: 1326555]

22. Jantzen HM, Strähle U, Gloss B, Stewart F, Schmid W, Boshart M, Miksicek R, Schütz G. Cooperativity of glucocorticoid response elements located far upstream of the tyrosine aminotransferase gene. Cell 1987;49:29-38. [PubMed: 2881624] 
23. Richardson J, Vinson C, Bodwell J. Cyclic adenosine-3',5'-monophsophate-mediated activationof a glutamine synthetase composite glucocorticoid response element. Mol Endocrinol 1999;13:546-554. [PubMed: 10194761]

24. Melvin VS, Edwards DP. Expression and purification of recombinant human progesterone receptor in baculovirus and bacterial systems. Methods Mol Biol 2001;176:39-54. [PubMed: 11554337]

25. Bodwell JE, Ortí E, Coull JM, Pappin DJC, Smith LI, Swift F. Identification of phosphorylated sites in the mouse glucocorticoid receptor. J Biol Chem 1991;266:7549-7555. [PubMed: 2019585]

26. Wang SY, Ahn BS, Harris R, Nordeen SK, Shapiro DJ. Fluorescence anisotropy microplate assay for analysis of steroid receptor-DNA interactions. BioTechniques 2004;37:2004.

27. Maitra R, Hamilton JW. Arsenite regulates Cystic Fibrosis Transmembrane Conductance Regulator and P-glycoprotein: evidence of pathway independence. Cell Physiol Biochem 2005;16:109-118. [PubMed: 16121039]

28. Davies TH, Ning YM, Sanchez ER. Differential control of glucocorticoid receptor hormone-binding function by tetratricopeptide repeat (TPR) proteins and the immunosuppressive ligand FK506. Biochemistry 2005;44:2030-2038. [PubMed: 15697228]

29. Evans RM. The steroid and thyroid hormone receptor superfamily. Science 1988;240:889-895. [PubMed: 3283939]

30. Freedman LP, Luisi BF, Korszun ZR, Basavappa R, Sigler PB, Yamamoto KR. The function and structure of the metal coordination sites within the glucocorticoid receptor DNA binding domain. Nature 1988;334:543-546. [PubMed: 3043231]

31. Umesono K, Evans RM. Determinants of target gene specificity for steroid/thyroid hormone receptors. Cell 1989;57:1139-1146. [PubMed: 2500251]

32. Danielsen M, Hinck L, Ringold GM. Two amino acids within the knuckle of the first zinc finger specify DNA response element activation by the glucocorticoid receptor. Cell 1989;57:1131-1138. [PubMed: 2500250]

33. Zilliacus J, Wright APH, Carlstedt-Duke J, Gustafsson J-Å. Structural determinants of DNA-binding specificity by steroid receptors. Mol Endocrinol 1995;9:389-400. [PubMed: 7659083]

34. Picard D, Yamamoto KR. Two signals mediate hormone-dependent nuclear localization of the glucocorticoid receptor. EMBO J 1987;6:3333-3340. [PubMed: 3123217]

35. Reichardt HM, Kaestner KH, Tuckermann J, Kretz O, Wessely O, Bock R, Gass P, Schmid W, Herrlich P, Angel P, Schutz G. DNA binding of the glucocorticoid receptor is not essential for survival. Cell 1998;93:531-541. [PubMed: 9604929]

36. Adams M, Meijer OC, Wang J, Bhargava A, Pearce D. Homodimerization of the Glucocorticoid Receptor is not Essential for Response Element Binding: Activation of the Phenylethanolamine NMethyltransferase Gene by Dimerization-Defective Mutants. Mol Endocrinol. 2003

37. Warren BS, Kusk P, Wolford RG, Hager GL. Purification and stabilization of transcriptionally active glucocorticoid receptor. J Biol Chem 1996;271:11434-11440. [PubMed: 8626700]

38. English AM, Wilcox DE. Effects of metal ions on the oxidation and nitrosation of cysteine residues in proteins and enzymes. Met Ions Biol Syst 2001;38:313-350. [PubMed: 11219014]

39. Stoica A, Pentecost E, Martin MB. Effects of arsenite on estrogen receptor-alpha expression and activity in MCF-7 breast cancer cells. Endocrinology 2000;141:3595-3602. [PubMed: 11014213]

40. Kralli A, Yamamoto KR. An FK506-sensitive transporter selectively decreases intracellular levels and potency of steroid hormones. J Biol Chem 1996;271:17152-17156. [PubMed: 8663352]

41. Lopez S, Miyashita Y, Simons SS Jr. Structurally based, selective interaction of arsenite with steroid receptors. J Biol Chem 1990;265:16039-16042. [PubMed: 2168876]

42. Simons SS Jr, Chakraborti PK, Cavanaugh AH. Arsenite and cadmium(II) as probes of glucocorticoid receptor structure and function. J Biol Chem 1990;265:1938-1945. [PubMed: 2298732]

43. Chakraborti PKHW, Groner B, Simons SS Jr. Localization of the vicinal dithiols involved in steroid binding to the rat glucocorticoid receptor. Endocrinology 1990:2530-2539. [PubMed: 2226332]

44. Thornton JW. Evolution of vertebrate steroid receptors from an ancestral estrogen receptor by ligand exploitation and serial genome expansions. Proc Natl Acad Sci U S A 2001;98:5671-5676. [PubMed: 11331759] 
45. Chow SK, Chan JY, Fung KP. Suppression of cell proliferation and regulation of estrogen receptor alpha signaling pathway by arsenic trioxide on human breast cancer MCF-7 cells. J Endocrinol 2004;182:325-337. [PubMed: 15283693]

46. Chen GC, Guan LS, Hu WL, Wang ZY. Functional repression of estrogen receptor a by arsenic trioxide in human breast cancer cells. Anticancer Res 2002;22:633-638. [PubMed: 12014631]

47. Tao Y, Williams-Skipp C, Scheinman RI. Mapping of glucocorticoid receptor DNA binding domain surfaces contributing to transrepression of NF-kappa B sand induction of apoptosis. J Biol Chem 2001;276:2329-2332. [PubMed: 11106637] 
Fig 1A

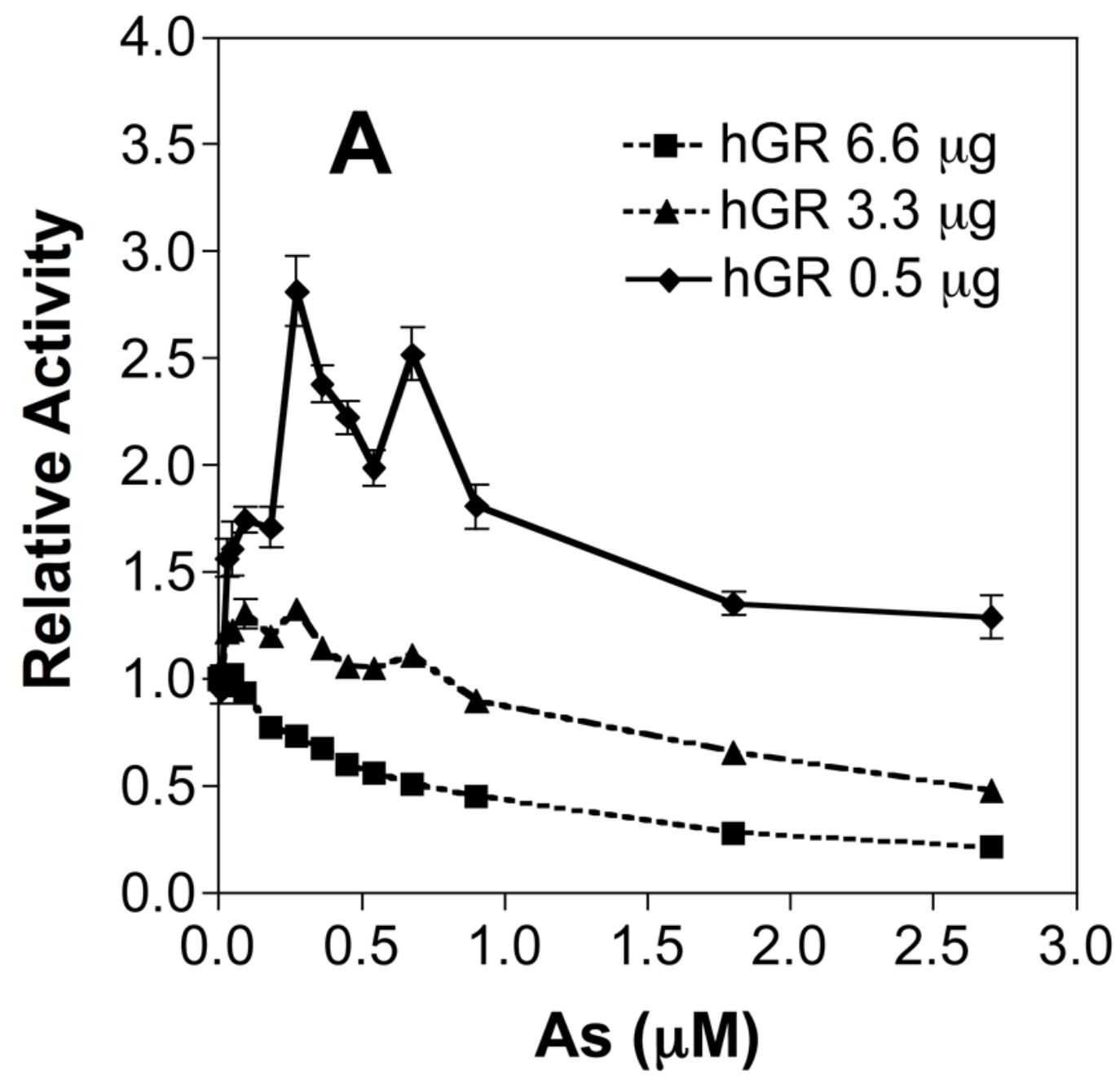

Chem Res Toxicol. Author manuscript; available in PMC 2008 September 30. 
Fig1B

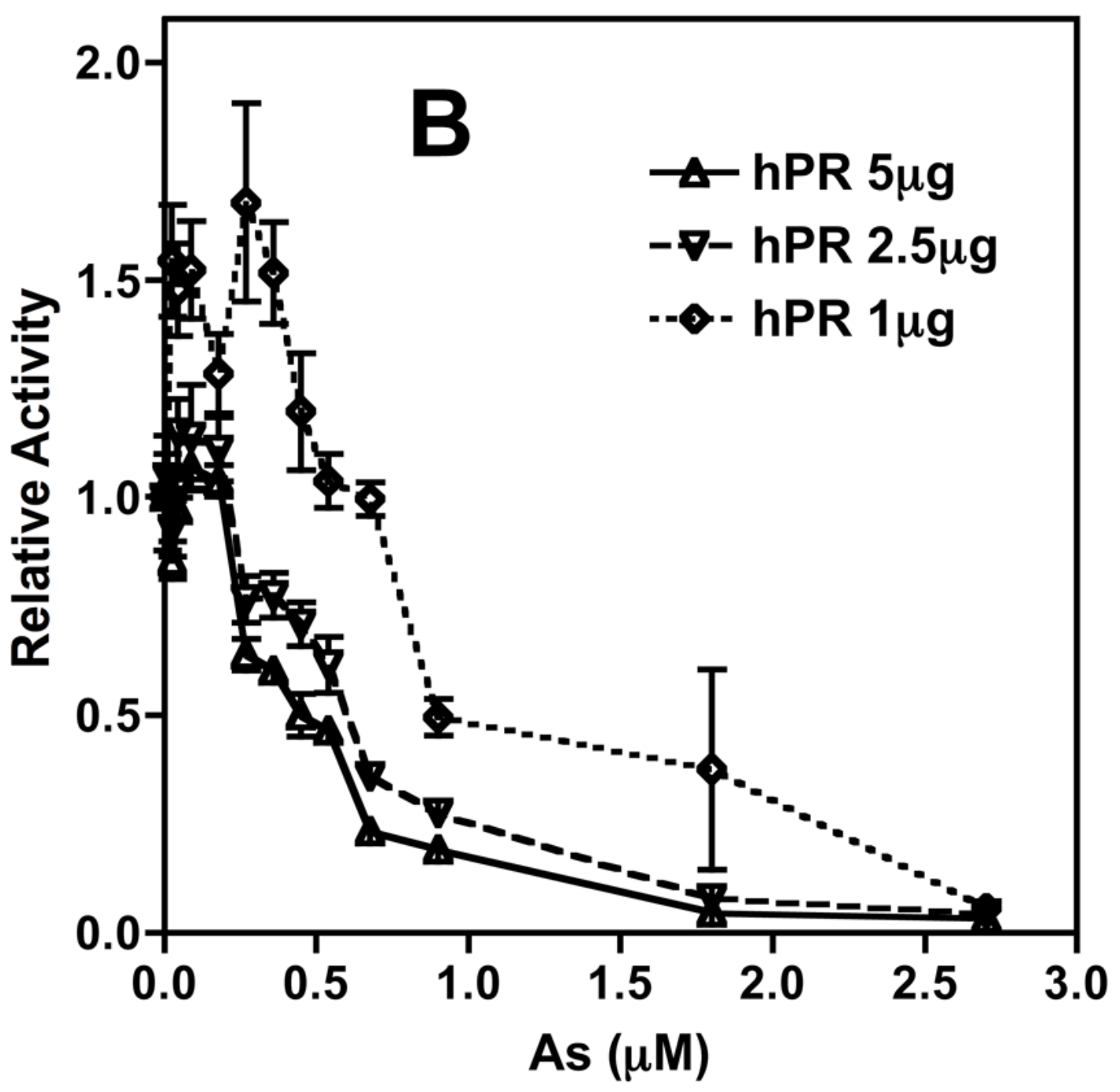


Fig1C

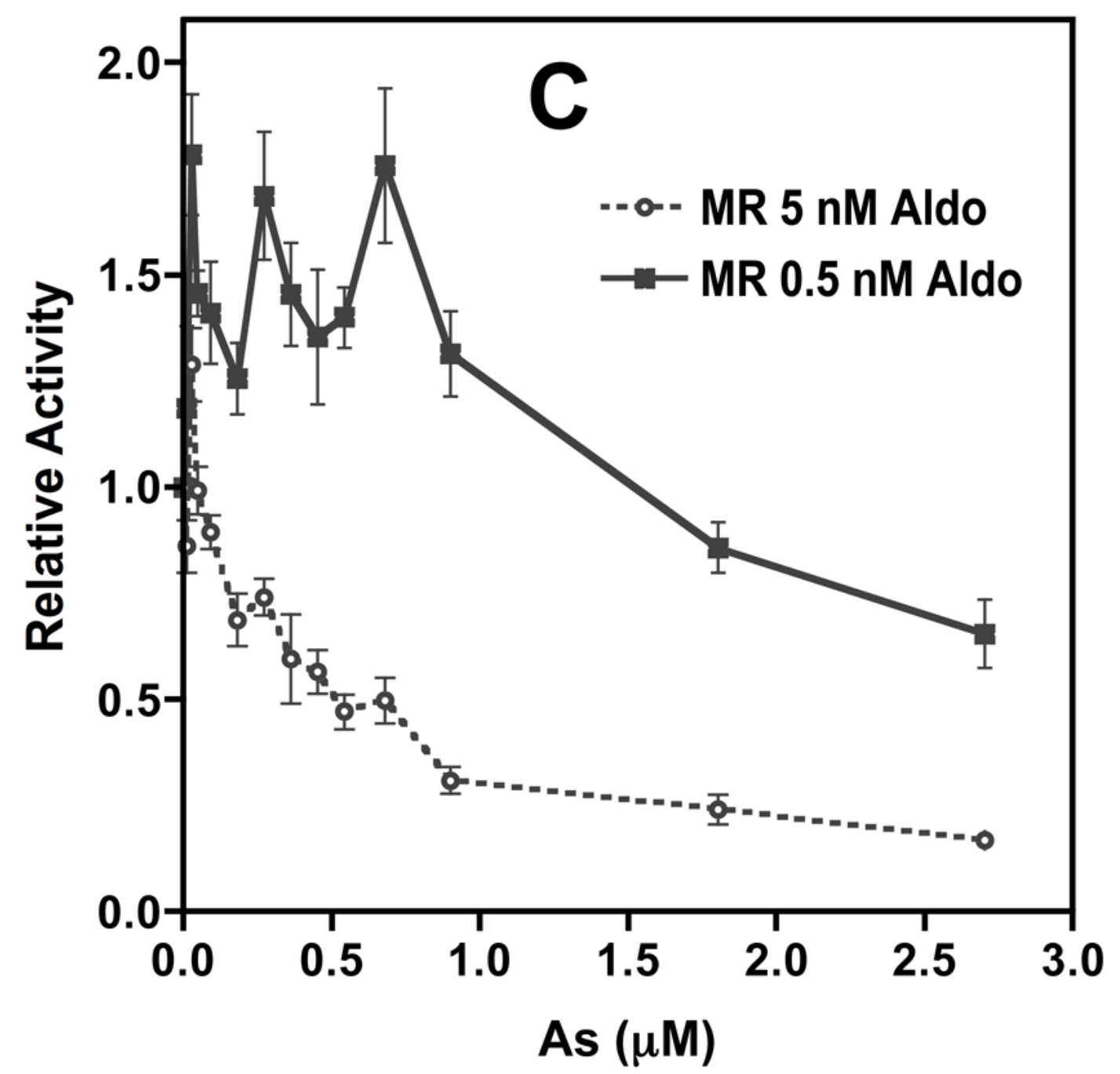

Figure 1. Other SRs have a biphasic response to As

Different amounts of DNA encoding hGR (pCMV5 hGR, Panel A, reproduced from (11)), hPR(pCR3.1 PRB, Panel B) or a single level of rMR (PCMV4/neo/MR, Panel C) were transfected into EDR3 cells with the G2T reporter gene as described in Experimental Procedures. Cells were treated with 50nM Dex (hGR), 50nM progesterone (hPR), or the indicated levels of aldosterone (rMR) with and without As (see Experimental Procedures for actual concentrations) for $\sim 18 \mathrm{hrs}$. Cells were processed and cytosols assayed for luciferase and protein as described in the Experimental Procedures. Figures 1-7 are representative of at least 3 independent experiments and each point is the mean of 6 replicates per point. Variation is presented as \pm SEM. For individual treatments, each point was divided by the value of the 
Dex without As treatment. This normalization to relative activity allows comparison of As effects on treatments that have different transcriptional activity. Dex without As values (kRLU/ $\mathrm{mg}$ ) for panel A (most to least transfected DNA) are 426.6, 249.3, and 57.8 with a $74 \pm 8$ average fold increase over no hormone values and for panel B 169.8, 138.7, and 72.5 ( $30 \pm 12$ fold increase). Values for panel C were 223.7 and 67.8 (8-5fold increase) for $5 \mathrm{E}-9$ and $5 \mathrm{E}-10 \mathrm{M}$ aldosterone respectively. 


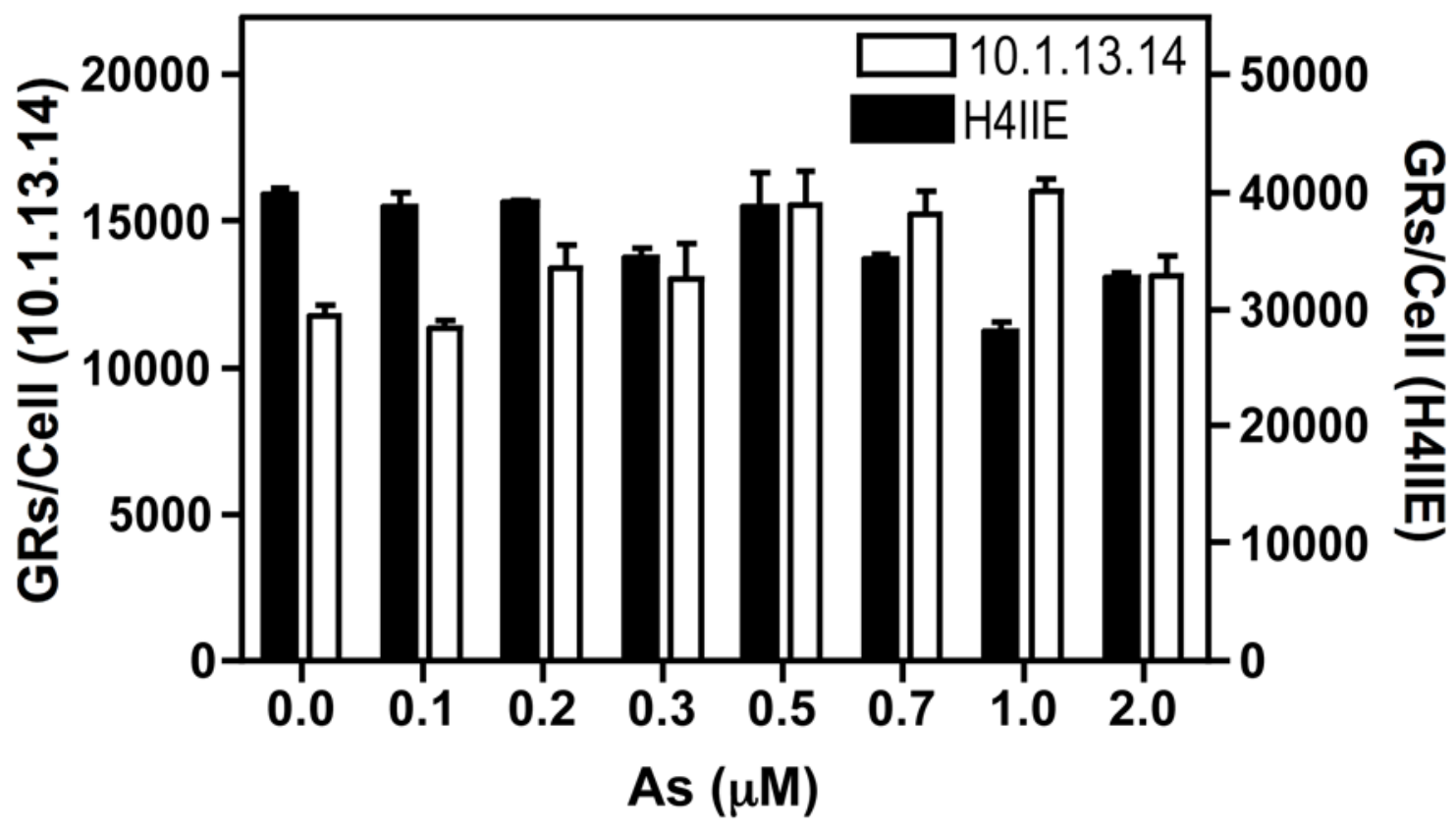

Figure 2. As does not affect SR hormone binding capacity

A whole cell hormone binding assay (see Experimental Procedures) was used to determine GR specific binding of $\left[{ }^{3} \mathrm{H}\right]-\operatorname{Dex}(20 \mathrm{nM})$ in 10.1 .13 .14 (EDR-3 cells stably expressing 10,00-5,000 mGRs/cell) and H4IIE cells (30,000-40,000 endogenous rGRs/cell). 


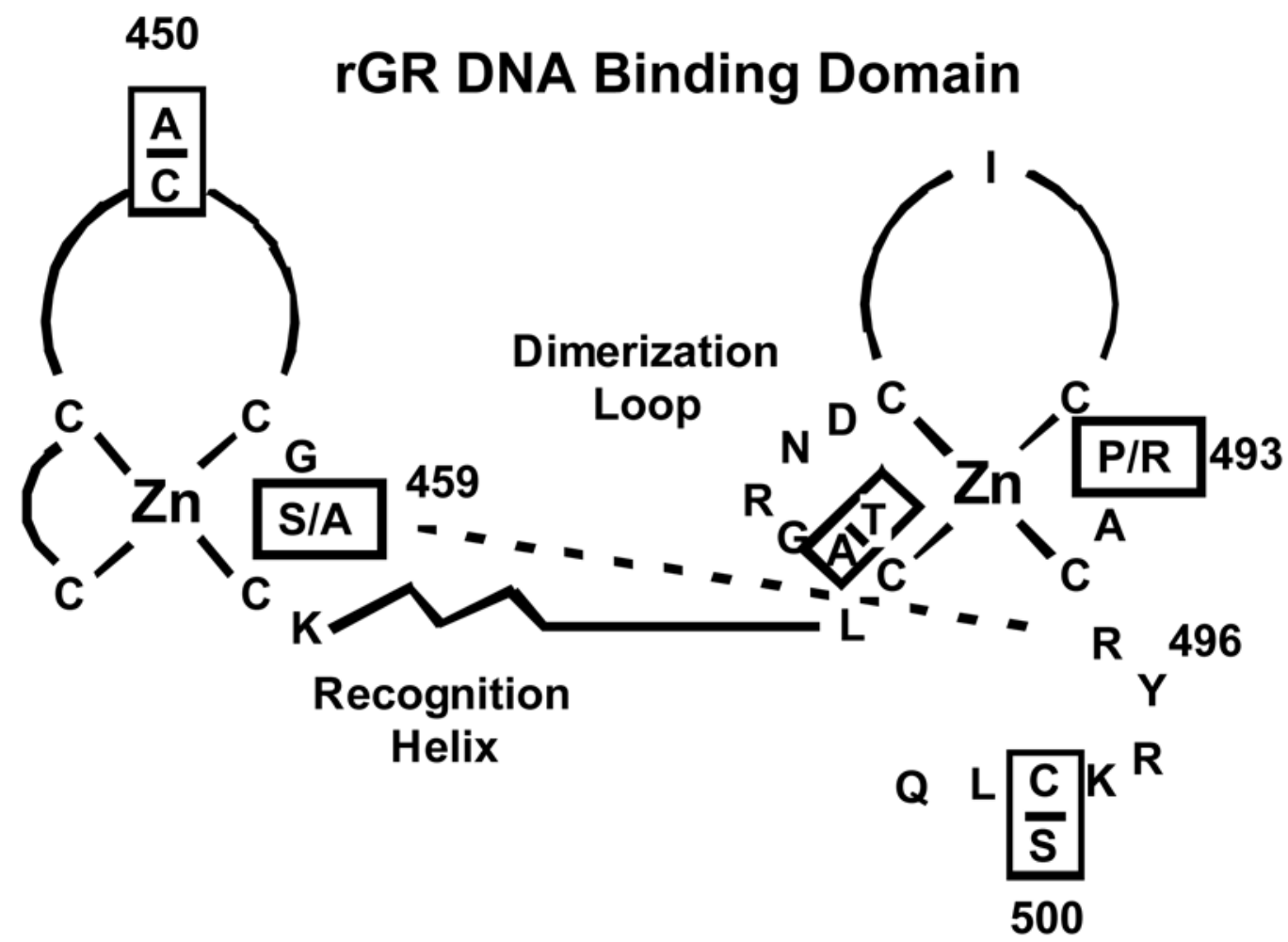

Figure 3. Location of mutants in the GR DBD known to alter the response to As

Schematic representation of the rGR DBD indicating the two zinc finger structures, the DNA recognition helix and the dimerization loop. Amino acid positions referred to in the text are numbered according to the rat structure. Point mutations producing the DNA bound conformation are in horizontal boxes. The H-bond between $\mathrm{S} 459$ to $\mathrm{P} 493$ is indicated by dashed line. Vertical boxes show mutations of the two free cysteines in the DBD and the tilted box shows the position of the $\mathrm{GR}_{\mathrm{dim}}$ mutation. 


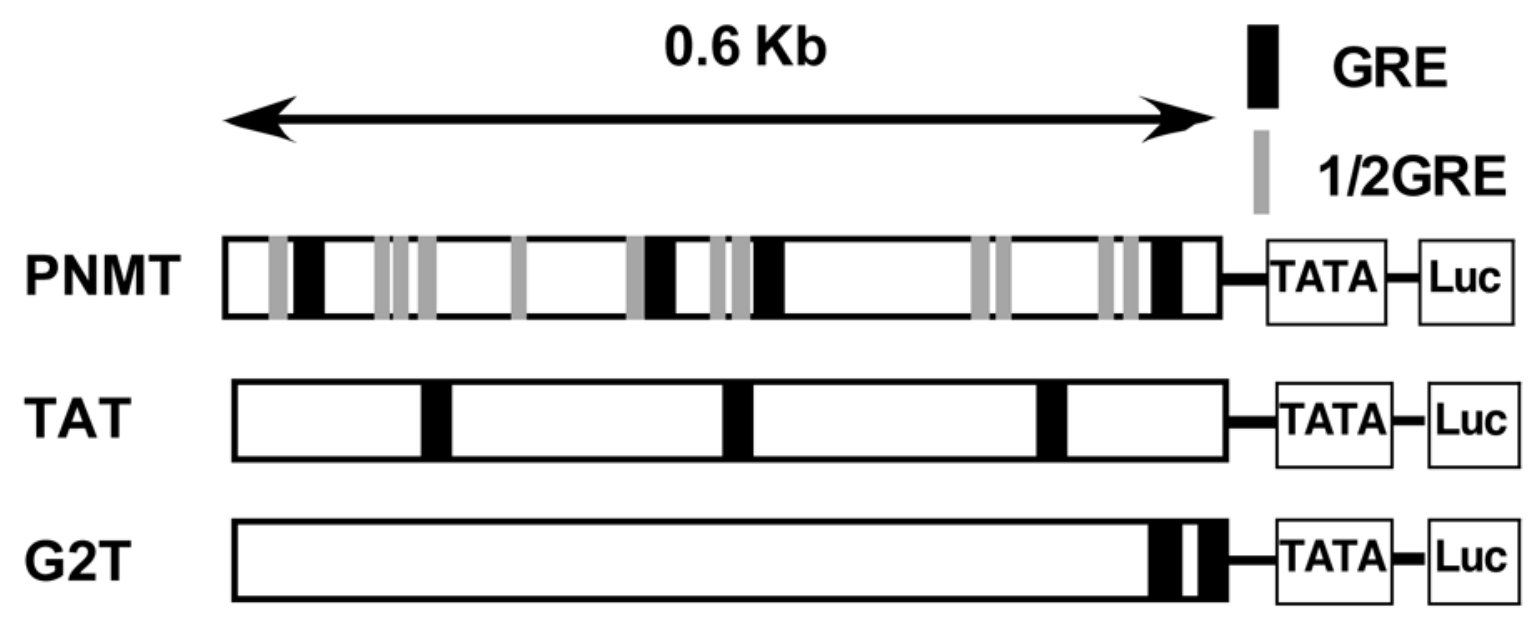

Figure 4. GRE configuration of luciferase reporter genes

Diagrammatic representation of thepromoter regions of the TAT-Luc ( -3079 to -2034$)$ and PNMT-Luc ( -977 to -513 ) genes used to evaluate GR $_{\text {dim. }}$. The pattern of GREs and 1/2GREs in each gene is compared to the G2T reporter gene. 


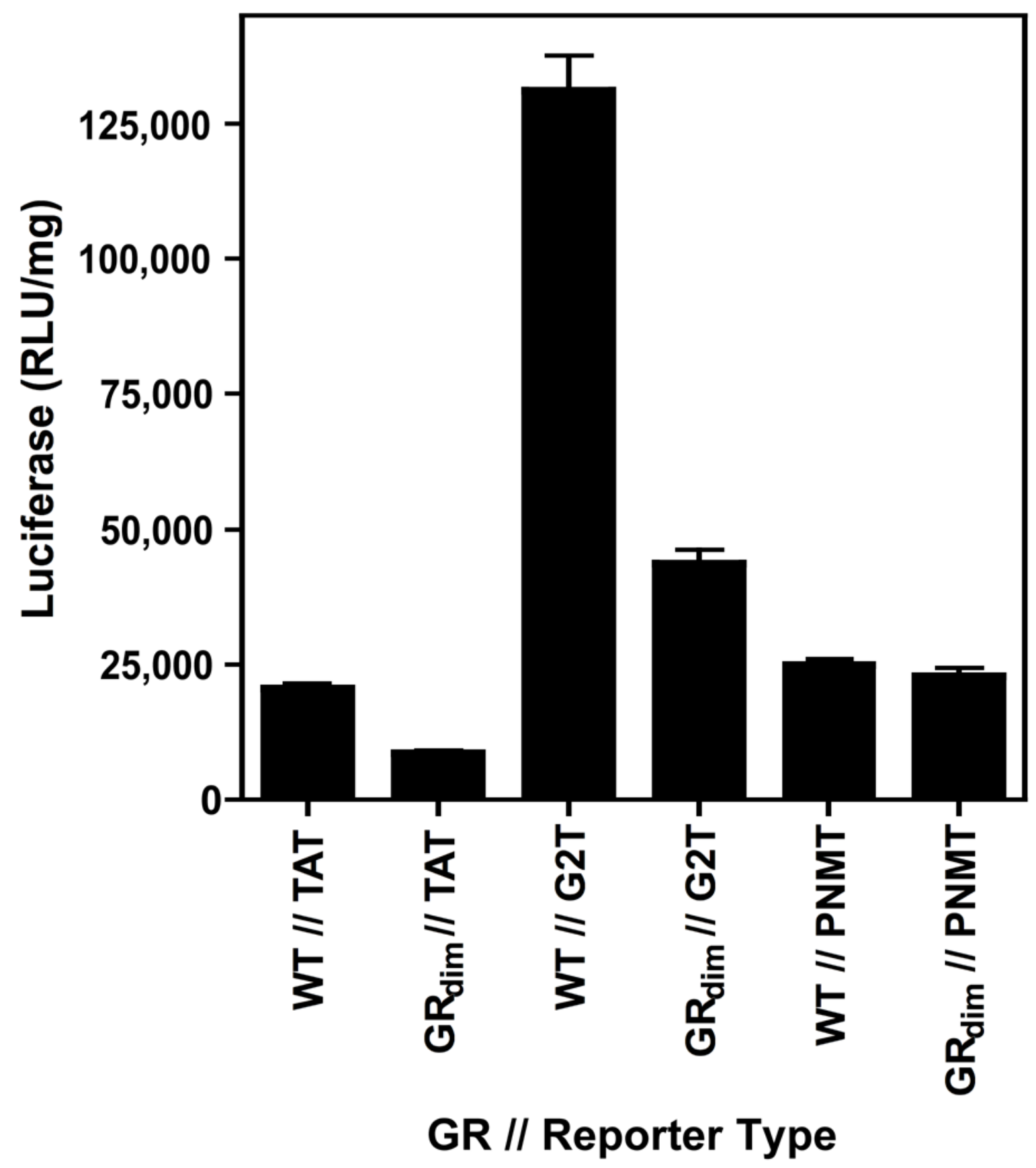

Figure 5. Characterization of the effect of $\mathbf{G R}_{\mathbf{d i m}}$ on reporter gene expression EDR-3 cells were transfected with the G2T, TAT-Luc or PNMT-Luc reporter genes and a range of concentrations of wildtype or $\mathrm{GR}_{\mathrm{dim}}$ encoding DNA. Cells were processed and resultant cytosols assayed as described in Fig 1. A whole binding assay was performed in order to be sure that treatments had comparable levels of GRs. Wild-type and $\mathrm{GR}_{\text {dim }}$ levels were equivalent for experiments using the TAT (3,000-4,000 rGR/cell) and the PNMT (4,000-5,000 rGRs/cell) reporters, while with the G2T reporter there was more $\mathrm{GR}_{\mathrm{dim}}(4800 \pm 2000 \mathrm{GRs} /$ cell) than wildtype (2700 $\pm 200 \mathrm{rGRs} /$ cell). Basal activity for wild type and $\mathrm{GR}_{\text {dim }}$ were 3.7 and $3.3 \mathrm{kRLU} / \mathrm{mg}$ respectively for TAT-Luc, 3.3 and 3.2 for G2T and 4.1 and 4.1 for PNMT- Luc. 


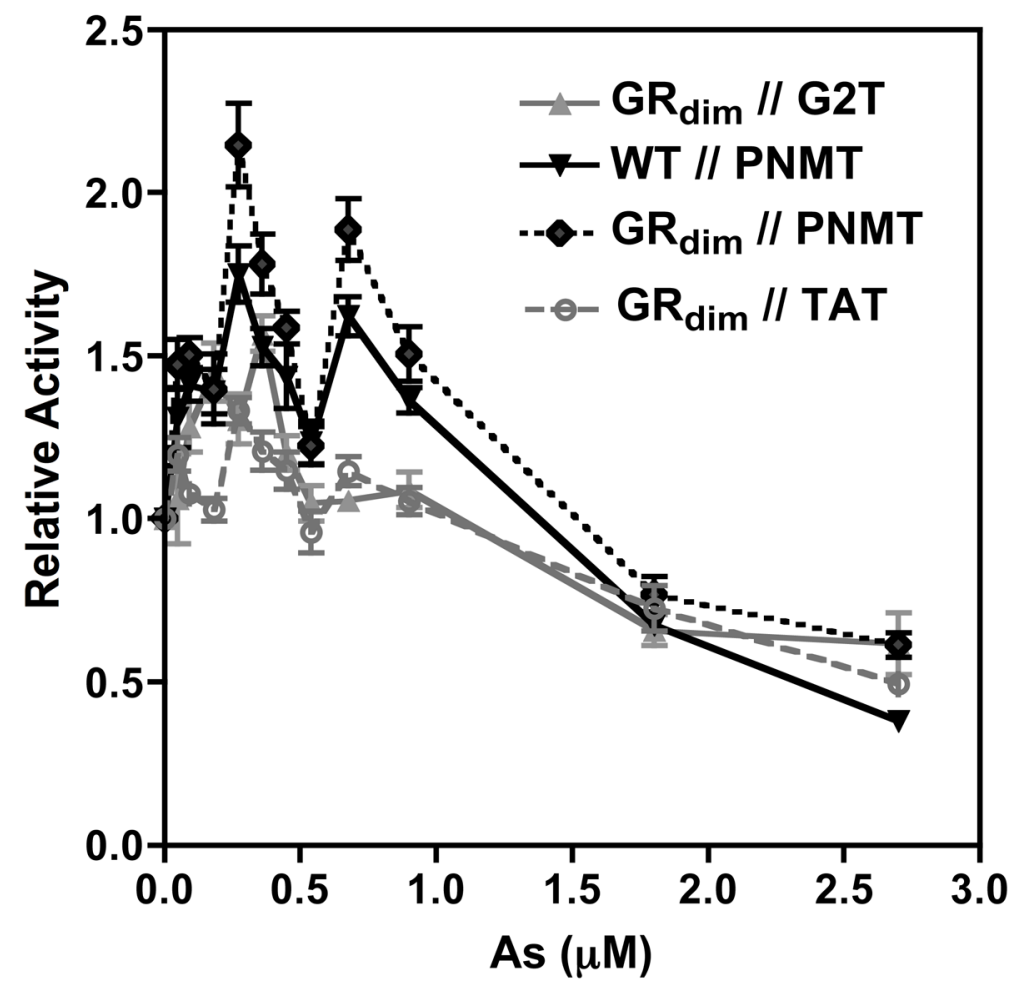

Figure 6. $\mathbf{G R}_{\operatorname{dim}}$ has a wildtype response to As

EDR-3 cells were transfected with GR $_{\text {dim }}$ or wildtype rGR along with the TAT-Luc, PNMTLuc or G2T reporter genes, treated with As, and processed as described in Fig 1. Dex without As values (and fold increase over basal) for Wt and $\mathrm{GR}_{\mathrm{dim}}$ were 20.6 (6.4) and 8.5 (3.5) kRLU/ mg respectively for TAT-Luc, 125.0 (38.0) and 47.0 (15.4) for G2T, and 24.2 (6.7) and 22.8 (6.4) for PNMT-Luc. 


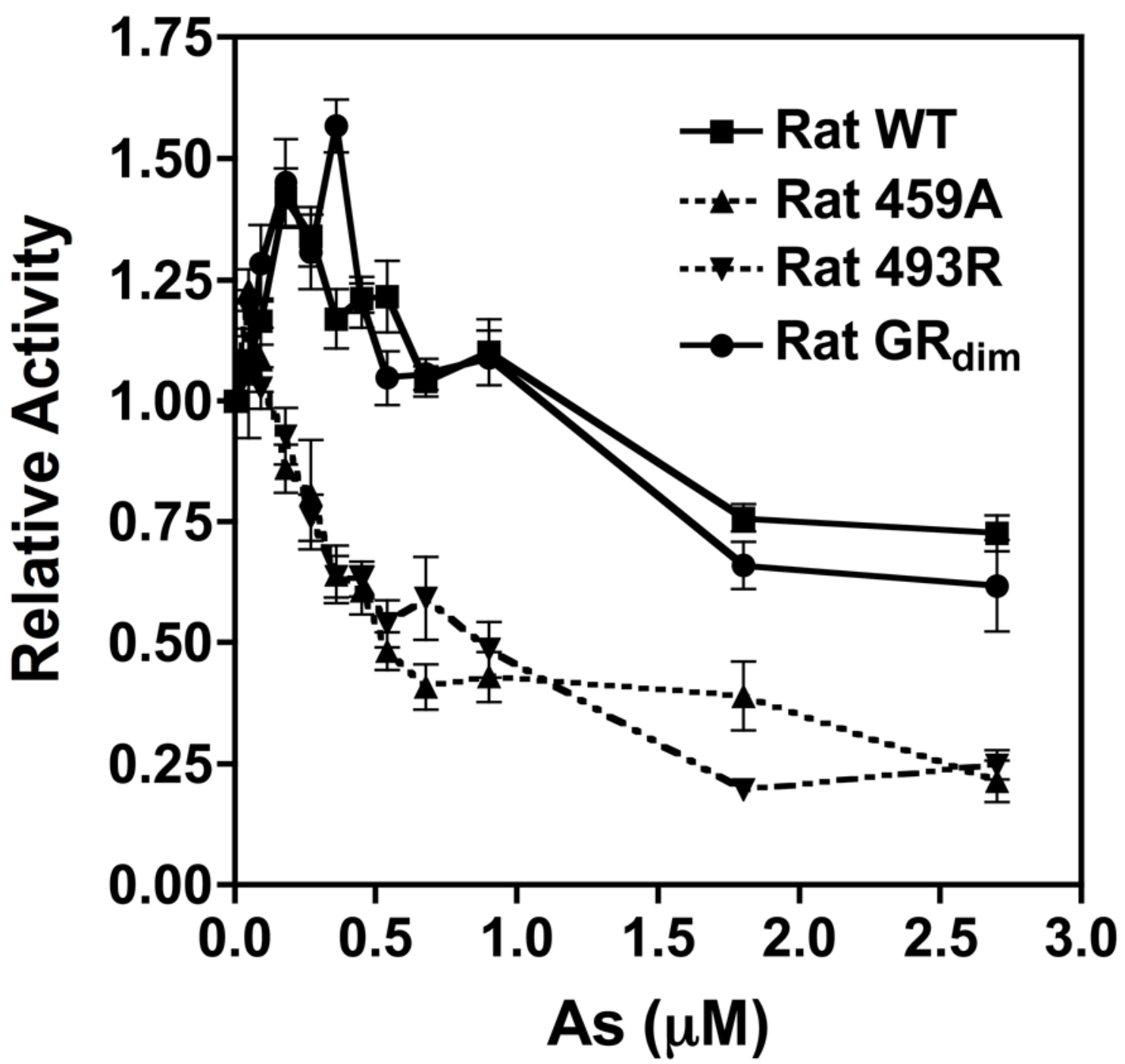

Figure 7. Comparison of $\mathbf{G R}_{\operatorname{dim}}$ and the DNA conformational mutants response to As The response of $\mathrm{rGR}$, and $\mathrm{GR}_{\mathrm{dim}}$ to As for the G2T reporter (Fig 6) is overlaid with the response for the two DNA conformational mutants (459A and 493R,(11)) to the same reporter. (Data for wt, 459A, and 493R reproduced from (11)) Dex without As values for $\mathrm{GR}_{\text {dim }}$ are listed in Fig 6 legend while those for WT, 459A and 493R had 69.8, 3.8, and 10.4 kRLU/mg respectively (11) 

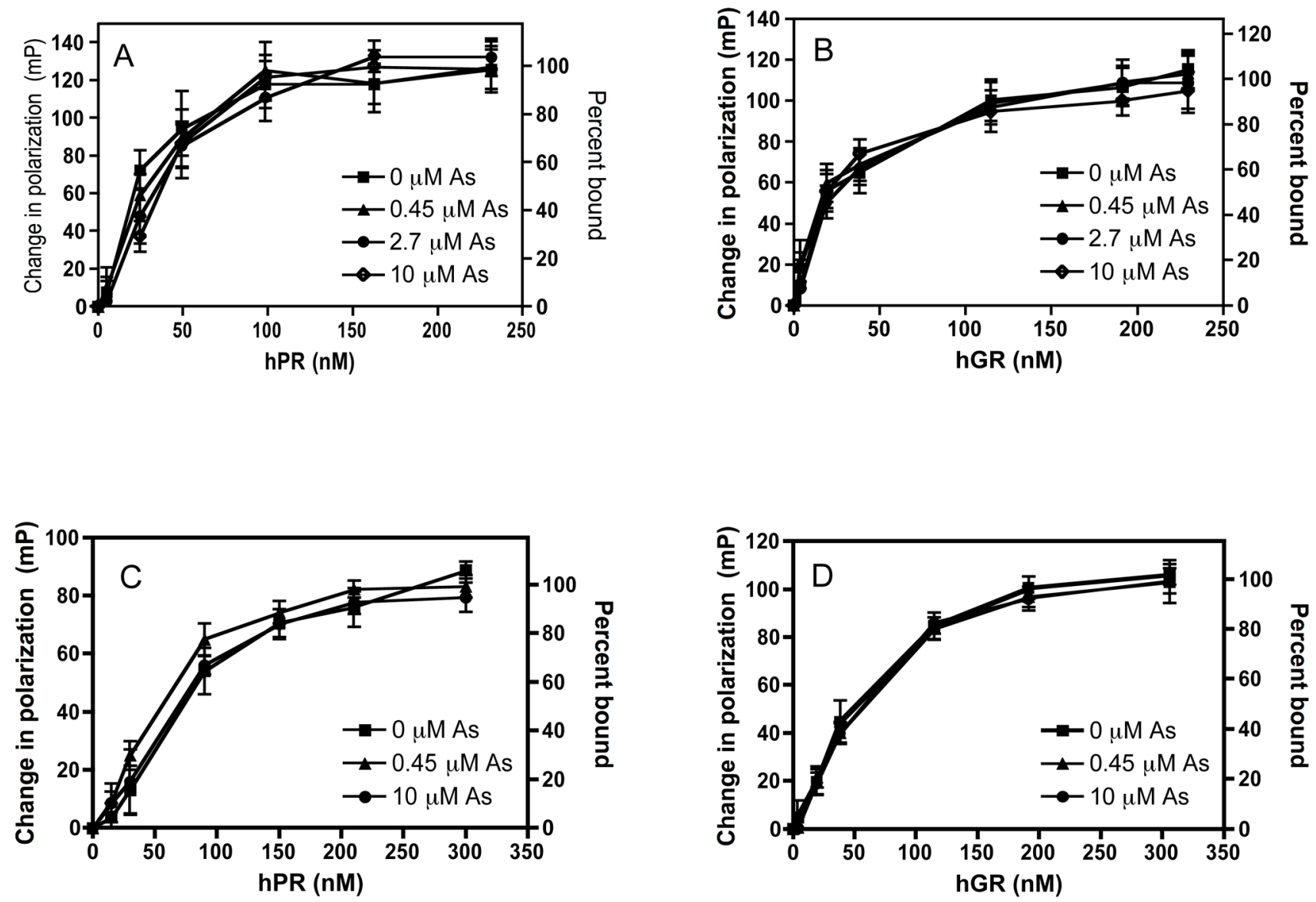

Figure 8. As does not affect equilibrium binding curves of hPR and hGR to FITC-G2T and FITCGT

Increasing amounts of hPR (Panels A and C) or hGR (Panels B and D) were incubated with 1 nM FITC-G2T (Panels A and B) or FITC-GT (Panels C and D) in FP buffer (plus $1 \mathrm{mM}$ GSH and $7.5 \mathrm{mM}$ CHAPS for hGR only) or with the indicated As concentrations. FP was measured as described in Experimental Procedures at equilibrium. "Change in polarization (mP)" represents the difference between polarization values measured at each concentration of receptor and the polarization measured with no added receptor. "Percent bound" was calculated as described in Experimental Procedures. Each binding curve is representative of two or three independent experiments. Three replicates were measured for each data point within each independent experiment, and the error bars shown are error-propagated standard deviations (see Experimental Procedures). 

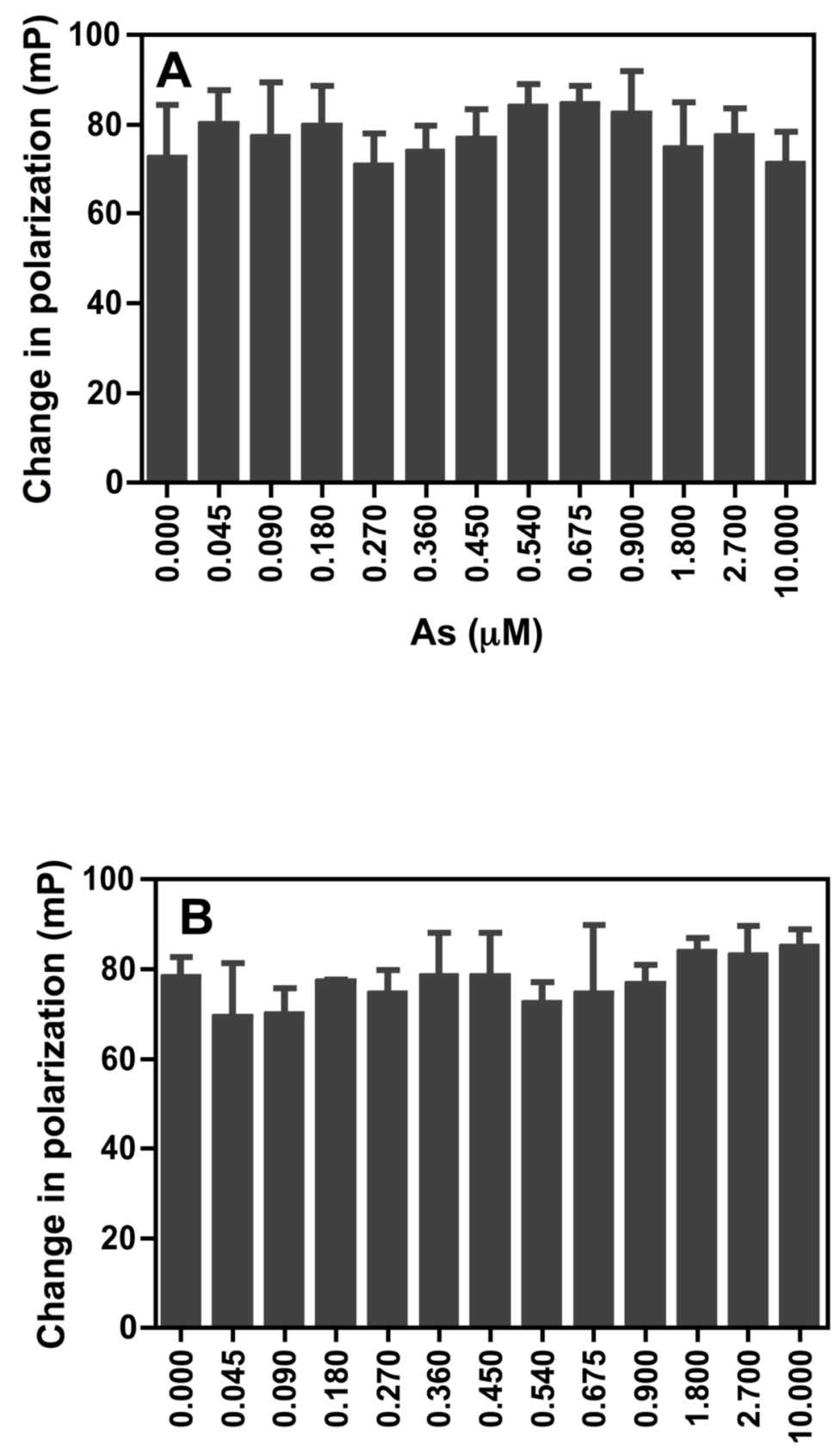

As $(\mu \mathrm{M})$

Figure 9. A wide range of As concentrations does not affect hPR (Panel A) or hGR (Panel B) binding to FITC-G2T

A fixed receptor level (approximately $70 \%$ of maximal binding) was incubated with $1 \mathrm{nM}$ FITC-G2T in FP buffer (plus $1 \mathrm{mM}$ GSH and $7.5 \mathrm{mM}$ CHAPS for hGR only) with varying levels of As (final concentrations are indicated on the X-axis). FP was measured as described in the Fig 8 legend. The data in each panel represent the average of two independent experiments, \pm average error. 